\title{
Quality of life in children with sleep-disordered breathing
}

\author{
Qualidade de vida em crianças portadoras de distúrbios respiratórios do sono \\ Amaury de Machado Gomes
}

Pós-Graduação em Neurociências da Fundação Bahiana para o Desenvolvimento das Ciências, Salvador BA, Brazil.
Orientadora: Manuela Garcia Lima
Co-orientadora: Márcia Lurdes Pradella-Hallinan
Correspondence: Amaury de Machado Gomes; Avenida ACM 2604; 40280-000 Salvador BA - Brasil; E-mail: amauryorl@gmail.com

\section{ABSTRACT}

Introduction: Children may present sleep-disordered breathing (SDB) that includes primary snoring (PS) and obstructive sleep apnea syndrome (OSAS). The golden-standard for diagnosis is polysomnography (PSG), and the main cause is adenotonsillar hypertrophy. Adenotonsillectomy is the most appropriate treatment. SDB leads to innumerable complications and impacts on quality of life (QOL), and to evaluate it, the use of questionnaires with answers from parents or caregivers is necessary. Objectives: To evaluate QOL in children with SDB, to compare the QOL of children with OSAS and PS, and to identify which areas of OSA-18 are mostly affected. Methods: Cross-sectional study with consecutive sampling of spontaneous demand in children with history of snoring and or apnea, with hyperplasia of tonsils or adenoids at physical examination. The obstruction degree of tonsils was identified by Brodsky's classification, pharyngeal tonsil (adenoid) was measured by fiberoptic nasal endoscopy and QOL by OSA-18 questionnaire. PSG was used to diagnose OSAS and PS according to apnea index (AI) and apnea-hypopnea index (AHI) and were calculated by dividing the number of apneas or hypopneas by the hours of sleep. Results: Fifty-nine children participated in this study with mean age of $6.7 \pm 2.26$ years-old. The mean score of the 0SA-18 was $77.9 \pm 13.22$ and the areas were: caregiver concerns (21.8 \pm 4.25$)$, sleep disturbance (18.8 \pm 5.19$)$, and physical suffering (17.3 \pm 5.0$)$. The impact was low in 6 children (10.2\%), moderate in 33 (55.9\%), and high in 20 (33.9\%). PS was found in 44 children (74.6\%), OSAS in 15 (25.6\%) and degrees were: mild in 6 (10.2\%), moderate in 1 (1.7\%), and severe in 8 (13.6\%). OSAS had most affected physical suffering area than PS ( $p=0.04)$. There was a lack of correlation between the OSA-18 score and the degree of pharyngeal obstruction $(r=0.18 ; p=0.17)$ and obstructive tonsils $(r=0.04 ; p=0.74)$. There was no difference between OSA-18 scores and the groups PS, OSAS mild, moderate, and severe $(p=0.07)$. The Al $(r=0.22 ; p=0.08)$ and $\mathrm{AHI}(r=0.14 ; p=0.26)$ were not correlated with OSA-18. Conclusions: SDB caused moderate to marked impact in the QOL and the most affected areas were caregiver concerns, sleep disturbance, and physical suffering. Those affected by OSAS had higher score in the field of physical distress than PS. OSA-18 did not correlate with PS, OSAS, Al, and AlH.

Key words: quality of life, children, sleep apnea, snoring, sleep-disordered breathing. 